\title{
Estimating a consistent and detailed time series of immigration and emigration for sub-state regions of Australia
}

ASAP-D-19-00003 (Revised 07 June 2019)

\begin{abstract}
The size and composition of the Australian population has shifted since the dismantling of the discriminatory White Australia Policy during the 1970s, yet its immigration system and border control remain highly regulated. Despite this, detailed information about the specific locations that immigrants arrive to or depart from within Australia are not available. The picture is further compounded by inconsistencies in the measurement of flows and geographic boundaries over time. To address these issues, we obtained available immigration and emigration flow data provided by the Australian Bureau of Statistics at the state and territory level, and developed methods to harmonise the available data, estimate missing elements and disaggregate to a sub-state geography. The methods are applied to 19 birthplace-specific populations across 47 areas in Australia for annual time periods from 1981 to 2016. This research addresses the need for more detailed estimates of demographic events so that a better understanding of the mechanisms and differences underlying regional population change may be provided.
\end{abstract}

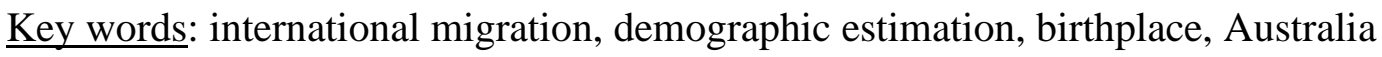

\section{Introduction}

In this paper we develop methods to provide a fuller understanding of regional population change generated by international migration over time. The methods focus on combining data from sources that are readily available, thereby allowing researchers and government agencies the means for more efficient usage of existing data, and to save money and time by 
overcoming the need for collecting new data. Australia provides a useful case study for developing such methods due to its high levels and diversity of immigration streams, and its considerable variability in population sizes across regional areas. Currently, $29 \%$ of the resident population in Australia is born overseas (ABS 2018c), with the largest immigrant groups born in the United Kingdom, New Zealand, China and India (see Appendix 1A). However, the detailed information needed to understand how these and other immigrant populations are distributed across space and evolving over time are not available (Wilson 2017).

The absence of detailed geographical data is a common problem for countries lacking population registers or for those who are reliant on multiple registration sources to compile their migration statistics. Australia is fairly unique in that it tracks all individual movements across its borders. However, the data are collected primarily to regulate visas at points of entry or exit (e.g., airports) and not for identifying where they live or to study population change. To determine the contributions to population change by immigration and emigration, border crossing data are processed by the Australian Bureau of Statistics to derive numbers that are meant to align with their national and state or territory demographic accounts.

Understanding how regional populations are changing below the state and territory scale is required for urban and regional planning, including the support intended for a wide range of public services. Moreover, sub-state population change is dominated by migration flows, whether international migration, internal migration or both (White 2016, p. 1). While the vast majority of immigrants arrive in the five major state capital cities of Sydney, Melbourne, Brisbane, Adelaide and Perth, smaller but important contributions are also made by immigrants in other areas of Australia, including the other three state and territory capital cities of Hobart, Canberra and Darwin (Charles-Edwards et al. 2015). Moreover, there are 
specific policies designed to steer migrants towards these areas, albeit with mixed success (Hugo 2008; Raymer and Baffour 2018).

Recently, Wilson (2017) proposed a methodology to estimate sub-state international migration flows for 49 regions in Australia during the 2006-2011 period. We extend this author's methods and ideas to estimate a considerably more detailed set of annual immigration and emigration flows by age and sex across 47 regions in Australia (Appendix 1B and 1C) for 19 birthplace-specific populations (Appendix 1A) from 1981 to 2016. In order to conduct this research, we had to overcome four major data challenges: (i) inconsistent geographic regions over time, (ii) inconsistent measurement of international migration over time, (iii), incomplete time series data on birthplace-specific migration flows, and (iv) missing sub-state immigration and emigration flows. The result of our efforts is a complete and consistent account of immigration and emigration that can be used to both study patterns of international migration and to determine the contributions of international migration to sub-state population change by age and sex. Note, there are many aspects of international migration and its effect on populations. We focus on flows by country or region of birth because of its unchanging nature over time. Unlike citizenship or ethnicity, one's birthplace does not change. Also, in Australia, there is a relative abundance of information on country of birth across different data sets in Australia, including censuses and administrative registers.

This paper is structured as follows. First, we review the literature on harmonising and estimating regional flows of international migration. Second, we describe the data that are available in Australia to study the changing regional patterns of international migration by country of birth from 1981 to 2016 . Here, we make a distinction between arrival (departure) data and immigration (emigration) data, as well as state and sub-state data. Third, we propose methods for harmonising state-level immigration and emigration data and distributing them 
to sub-state regions. Fourth, we demonstrate the value of such estimates by describing the major changes that have occurred to five major immigrant groups from 1981 to 2016 . These case study immigrant groups consist of those born in New Zealand, the United Kingdom, China, South-Eastern Europe and Vietnam. These groups have been chosen primarily because they represent large immigrant populations who have experienced profoundly different immigration histories and geographies. For comparison reasons we also include immigration and emigration flows of persons born in Australia. For this group, immigration refers to persons who have previously emigrated and have returned to their country of birth. The paper ends with a discussion and conclusion.

\section{Background}

The population of Australia has been growing at a relatively high rate for much of its nonAboriginal settlement history, with a substantial proportion of that growth generated by immigration. The volume of international migration increased substantially from the mid1990s onwards with the introduction of temporary migration visas (Hugo 2014). Since the mid-2000s high levels of net international migration have been responsible for about $60 \%$ of population growth and have led to greater population diversity in terms of country of birth (ABS 2014). In 2016, the estimated resident population was 24.2 million persons, an increase of nearly 10 million since 1981 (ABS 2014, 2017). Indeed, the fraction of the population born overseas in 2016 was the highest it had been in over 120 years (ABS 2016). As a result of this immigration, Australia is now considered one of the most ethnically diverse populations in the world (Jupp 2001; Castles et al., 2014, p. 166).

The increasing diversity of international migration to Australia has been extensively studied (Hugo 1986; Jupp 1995; Khoo 2002, 2003; Khoo et al. 2011; Markus et al. 2009; Price 1998; Wilson and Charles-Edwards 2017; Wilson and Raymer 2017; Raymer et al. 
2018). However, compiling and estimating the immigration and emigration flows to study the demographic effects on sub-state regions for different immigrant groups and their trajectories over a long period of time has not been undertaken previously. This work thus complements and extends earlier research and provides a much needed basis for understanding the diversity of patterns of international migration to and from areas within Australia.

Approaches to estimate subnational international migration flows have varied greatly depending largely on the data available. In the United States, for example, data on emigration are not captured by any official statistics agency (Van Hook and Zhang 2011). Warren and Peck (1980), Warren and Kraly (1985), and Ahmed and Robinson (1994) developed techniques to indirectly estimate foreign-born emigration as the residuals from demographic accounting equations. This method assumes both populations at time $t$ and $t+n$ are known, and that information on births, deaths, and immigration are accurate. In this case, emigration is equal to the population at time $t$ minus the population at time $t+n$ plus births minus deaths plus immigration. Rogers and Raymer (1999), on the other hand, after finding residual techniques produced unreasonable estimates for subnational areas in the United States, developed their own method for estimating regional emigration flows. They used the 19551960 national emigration estimates from Warren and Kraly (1985) as a basis for estimating subsequent periods to $1985-1990$. Specifically, the ratio of the 1960-1965 to 1955-1960 level of immigration was used to infer the 1960-1965 level of emigration using the 1955-1960 estimated level of around 200 thousand emigrants as a starting point. This process continued until national estimates of emigration for all five-year periods were obtained. Similarly, regional levels were estimated based on observed patterns in the immigration flows, where regions that received larger numbers of immigrants were also assumed to have sent higher numbers of emigrants. 
Another way to estimate detailed flows of immigration or emigration is to decompose available flows for large geographic regions into smaller units according to auxiliary data sources. For example, Boden and Rees (2010) proposed producing local authority estimates of immigration in the United Kingdom using registers on health services, national insurance and higher education, benchmarking them to the national level estimates provided by the International Passenger Survey. Based on their research, the Office for National Statistics have since adopted a similar model to produce their local authority estimates of international migration (ONS 2018).

Akin to Rogers and Raymer (1999), Wilson (2017) found that residual methods for estimating sub-state emigration in Australia resulted in implausible results due to implicit errors in the population totals or other demographic events. He thus proposed a methodology for estimating sub-state immigration and emigration flows for the total Australian population during the 2006-2011 period. Regional immigration levels by age and sex were estimated using recent five-year interval census immigration data. The method for estimating sub-state emigration differed for Australian citizens and foreigners. Census population totals on Australian citizens and foreigners by visa category were used as a basis for disaggregating the state-level estimates.

In summary, there are many methods that can be used to estimate detailed immigration and emigration patterns. The estimation methods have depended largely on the available data sources and the particular population groups of interest. Countries that do not directly measure international migration flows are often forced to estimate the contributions of international migration as a residual from a demographic accounting equation. This can include emigration if census immigration data are available or net international migration if only population change and natural increase are known. In either case, residual estimates are likely to contain errors from the measured populations or vital registration data. Countries 
that collect international migration flow data from the border, such as the United Kingdom and Australia, have a somewhat better situation where missing subnational flows may be inferred from auxiliary data. Thus, in this paper, we extend and adapt the efforts by Boden and Rees (2010) and Wilson (2017) to develop detailed subnational estimates of international migration from and to Australia.

\section{Data}

This paper draws on three sources of international migration data produced by the Australian Bureau of Statistics: Overseas Arrivals and Departures (OAD) statistics, Net Overseas Migration (NOM) arrivals and departures estimates, and the quinquennial Australian censuses. The availability of these data over time and measurement types are summarised in Table 1. Our estimation strategy focuses on the NOM arrivals and departures data as they capture the measures needed to quantify the annual contributions of immigration and emigration, respectively, to demographic change.

\section{----- Table 1 about here -----}

Annual OAD event and Census five-year transition data are used to augment the missing information in the publically available NOM data, as described in Section 4. Our assumptions are based on findings from research on internal migration that found transition and event data to be highly correlated with each other (Rees 1977; Nicholson 1990; Rogerson 1990; Rogers et al. 2003; Raymer et al. 2007). However, in terms of determining levels of migration, one-year transition data tend to be lower than annual event data, and that one cannot simply multiply one-year transition data by five years to get a five-year transition flow. That said, both event and transition (one-year / five-year) measures of migration can be used to estimate and project populations so long as the population accounting framework is aligned to their measurement (Rees 1985; Rees and Willekens 1986; Raymer et al. 2015). 
OAD statistics include permanent and long-term arrivals and departures and exclude less than 12-month (short-term) visa holders and travellers for the estimation of usual resident population. These data are collected by the Department of Home Affairs from various sources, including incoming passenger cards, passports and visas (ABS 2018a). The selfreported nature of incoming passenger cards remains a source of concern over the quality of OAD data. A new imputation method was adopted in 2007 to account for missing information in the passenger card data. In 2013, the OAD statistics system was overhauled, resulting in a revised series of flow data from July 2004 to December 2013 (ABS 2018b).

NOM arrivals and departures measure the immigration or emigration flows necessary for determining population change. These flows are estimated from OAD statistics by the Australian Bureau of Statistics (ABS 2018c; see also Temple and McDonald 2018), where the 'net' in 'net overseas migration' refers to the extraction of records from the OAD statistics of persons who should (not) be considered as part of the population, and not the difference between inflows and outflows. Since July 2007, the estimation of NOM has been based on a 12 out of 16 month rule, whereby an arrival is defined as someone who has come from overseas and has lived in Australia for a total of 12 months over a period of 16 months. Likewise, a NOM departure is someone who has travelled overseas and has been away for 12 out of 16 months. Prior to July 2007, NOM arrivals (departures) were counted using a 12month continuous stay in (departure from) Australia. The rationale behind the change in criteria was to make a better distinction between short-term temporary movers and long-term migrants and especially international students enrolled in three- or four-year courses who return home for a few weeks each year (ABS 2018d).

Censuses are able to measure immigration to specific (sub-state) locations within Australia by cross-tabulating questions on current place of usual residence with place of residence one-year or five-years prior to the census. Here, immigrants are identified by 
stating "overseas" as their usual residence one year or five years ago. Also, immigrant populations and their characteristics are measured using the question on country of birth. The main limitations of the census data are that they are unable to measure emigration and the immigration of persons less than one year of age. Furthermore, immigration numbers represent transitions from country of residence five years ago to place of residence at the time of the census, whereas the OAD and NOM data are based on events approximating a oneyear period.

The OAD, NOM and census data used in this research are all disaggregated by sex, age and birthplace but with differences in availability over time and across space. The OAD data covers the period from 1981 to 2013, whereas the NOM data are only available by birthplace from 2004 to 2016. Furthermore, the OAD data are unspecified by birthplace from 1981 to 2003. They contain just the numbers of arrivals and departures and the estimates of category jumping, which refers to persons whose self-stated duration of stay differs from their actual duration, for instance, the number of people switching from a short visit to a stay exceeding one year. The need for including category jumping in the estimation processing was eliminated in 2006 with the transition to the 12 out of 16 month actual duration of stay method (ABS 2018c; Temple and McDonald 2018).

Both NOM and OAD data are available at the state and territory level but not at the sub-state region level. A further complication is that the sub-state geographic units varied considerably during the 35-years of this study. To deal with the inconsistent sub-state geographic boundaries over time, all Statistical Division or Statistical Area Level 3 geographic data (ABS 2018e) were converted into a consistent set of 47 geographic areas as described in Raymer and Baffour (2018; see also Blake et al. 2000 for an earlier application based on smaller geographic areas) and presented in Appendix 1B and 1C. 
Finally, for the purposes of illustrating the methodology we focus on the NOM arrivals and departures for persons born in

i. Australia, representing the majority population,

ii. New Zealand, representing a neighbouring country with no visa restrictions,

iii. the United Kingdom, representing a long-standing and large immigrant source population,

iv. South-Eastern Europe, representing a large immigrant group recruited after World War II under the White Australia policy,

v. Vietnam, representing a large humanitarian group who arrived after the Vietnam War, and

vi. China, representing a large and relatively new emerging immigrant group of international students and skilled workers.

Fig. 1 shows the comparison of the available time series of OAD and NOM data. It can be seen that the gaps between OAD statistics and NOM statistics increased since 2004 for persons born in the United Kingdom, China and Vietnam, whereas such gaps for those born in South-Eastern Europe and New Zealand remained relatively small. For the Australian-born flows, there were substantial differences between the OAD and NOM departure measures but not so for the corresponding immigration measures.

----- Figure 1 about here -----

\section{Methodology: Detailed estimates of immigration and emigration over time}

The approach to develop a set of consistent and detailed estimates of NOM arrival and departure flows from 1981 to 2016 can be split into two parts: first, estimating the NOM arrivals and departures at the state and territory level by birthplace in 1981-2003, and second, disaggregating the state-level estimates to $47 \mathrm{sub}$-state regions. We make use of the complete time series of OAD data and available NOM data from 2004 to 2016 in the first part, and 
achieve the second part by using both census data on country of birth and country of residence five-years ago.

\subsection{Estimating state-level immigration and emigration by birthplace}

As discussed above, the time series of NOM arrivals and departures by country of birth at the state and territory level is only available from 2004 and onwards. Therefore, the first step of this research was to estimate the historical time series from 1981 to 2003. Since NOM data are determined from long-term overseas arrivals and departures (OAD) data, we can extend the time series of estimated NOM flows based on average observed ratios of estimated NOM to OAD. In doing so, we make the assumption that the ratios remain constant by country or region of birth for immigration and emigration separately. We believe this provides a pragmatic solution in the absence of better data. In examining the observed NOM to OAD ratios by country or region of birthplace from 2004 to 2013, we noticed a distinct difference in the ratios before and after 2009. This is likely a consequence of immigration policy changes that occurred during 2009 and 2010, which had the effect of increasing the number of temporary arrivals (Parliament of Australia 2010). Therefore, for estimation of the 1981 to 2003 NOM arrivals and departures, the average 2004-2008 NOM to OAD ratios are used.

In Fig. 2, the average NOM to OAD ratios for immigration and emigration of females born in Australia, New Zealand, United Kingdom, South-Eastern Europe, Vietnam and China are presented by age. These ratios capture the relative difference between persons changing their country of usual residence based on the 12/16 month rule (NOM arrivals) and persons arriving on long-term visas (OAD arrivals). Note, as Australian-born and New Zealand-born arrivals (departures) are unlikely to require visas to enter, the difference between NOM and OAD are assumed to be related to the difference between their actual and intended length of stay (as stated in their passenger arrival / departure cards) in Australia or overseas. As shown 
in Appendix 2, these ratios are remarkably consistent across the larger states. In cases where state or territory patterns deviate from the overall age-specific pattern, the reason is likely due to the relatively small numbers underlying the patterns or age groups.

----- Figure 2 about here -----

Consider the average 2004-2008 Australia-born female ratios of NOM to OAD arrivals by age presented in Fig. 2A. Here, the ratios begin around 0.65 for the $0-4$ year olds and increase to 1.16 for the $15-19$ year olds and then drop to 0.81 for $30-34$ year olds and then gradually increase 1.5 and beyond in the remaining age groups. These ratios suggest that the Australia-born are more likely to visit (long-term) from overseas when they are children and when they are between ages 25 and 44 years old. On the other hand, immigration (or return migration) of Australia-born persons from overseas is more likely to occur when they are teenagers or young adults and after age 50 years. For the corresponding NOM to OAD departures presented in Fig. 2B, the age-specific ratios are all below 1.0 except for 0-4 year olds (1.18). This simply implies that there are more Australia-born persons taking extended leave than changing their place of residence to another country.

The average 2004-2008 age-specific ratios for the five immigrant groups in Fig. 2 show considerable variation from each other. Interestingly, both the NOM to OAD arrivals ratios and NOM to OAD departures ratios for New Zealand are often above one --- likely due to the free movement allowed between the countries. Vietnam and China tend to have low ratios in relation to the other four population groups.

The historical time series of birthplace-specific NOM flows were estimated from 1981 to 2003 by applying the average NOM to OAD ratios observed between 2004 and 2008 . These 'preliminary' estimates were further constrained by the reported total flows of immigration and emigration available by age, sex and state or territory from 1981 to 2003. This two-step procedure allowed us to obtain a consistent and complete time series of 
immigration and emigration flows from 1981 to 2016 for 19 birthplace-specific population groups by age, sex and state or territory.

\subsection{Estimating sub-state NOM arrivals by birthplace}

To estimate birthplace-specific NOM arrivals to each of the 47 sub-state regions by age and sex, we disaggregated our state-level estimates using sub-state census immigration counts:

$$
\hat{I}_{j b x y t}=I_{J b x y t} \times \frac{K_{j b y T}}{K_{J b y T}}
$$

where $I$ denotes an estimated NOM arrival flow, $b$ denotes country or region of birth, $j$ denotes one of the 47 areas in Australia, $J$ denotes the corresponding state or territory (i.e., $j \in J$ ), $x$ denotes age group, $y$ denotes sex, $t$ denotes a specific calendar year from 1981 to 2016, $T$ denotes a corresponding five-year intercensal period from 1981-1986 to 2011-2016 (i.e., $t \in T$ ), and $K$ denotes the census population overseas five-years ago. The age-specific patterns reported in the NOM estimates were assumed constant across sub-state regions.

With regard to the calculation of the census population ratio, consideration was given to whether NOM arrivals should be proportioned based on the numbers of persons overseas five years ago or one year ago. We compared the ratios of the Australia-born females who were overseas one year ago in the 2006 census with those who were overseas five years ago in the 2011 census and we found no noticeable differences between the two, except in Darwin and Northern Territory Outback. We decided on the five-year transition data because they are less susceptible to random shifts in relation to the one-year transition data. Also, they cover the whole five-year interval between censuses.

The census population ratios used in the equation above to distribute the NOM arrivals to specific sub-state regions are presented in Appendix 3. For example, the proportion of China-born female immigrants to New South Wales (NSW) going to Sydney 
during the 2011-2016 period was 0.9529 . This proportion was applied uniformly across all age groups.

\subsection{Estimating sub-state NOM departures by birthplace}

Birthplace-specific NOM departures from each of the 47 areas were estimated similarly to NOM arrivals, except that the sub-state proportioning was based on the numbers of persons born in birthplace $b$ aged 20-44 years living in area $j$ :

$$
\widehat{E}_{j b x y t}=E_{J b x y t} \times \frac{P_{j b y T}}{P_{J b y T}}
$$

where $E$ denotes annual NOM departures, $j$ the sub-state region of departure, $J$ the state to which the corresponding sub-state region belongs (i.e., $j \in J$ ), $t$ denotes a specific calendar year from 1981 to 2016, $T$ denotes a corresponding five-year intercensal period from 19811986 to 2011-2016 (i.e., $t \in T$ ), and $P$ the population aged 20-44 years considered most "at risk" of departing.

Since census data provides no direct measure of emigration, the population most "at risk" of emigration was used in the calculation. In choosing this group of the population, we compared the census population aged 20-44 years with those aged 15-49 years, using the China-born population in the 2011 Census as a test case. We found that the census population ratios were nearly the same for both ratios for both females and males. In general, agespecific patterns of migration are known to be dominated by young adults (Rogers and Castro 1981). Therefore, we expect younger immigrant populations (e.g., China-born) to produce relatively more emigration than the more established immigrant populations (e.g., United Kingdom-born).

Given that censuses are only conducted every five years, we also needed to decide which census to use for years in the intercensal period. Using the China-born females as a 
testing sample, we calculated census population proportions, i.e. $\frac{p_{j}}{p_{J}}$, for each census year from 1986 to 2016. The results, along with the corresponding immigration proportions, are presented in Appendix 3 for the periods 1981-1986, 1991-1996, 2001-2006 and 2011-2016. No significant changes in the area-to-state proportions can be observed throughout the seven census years. The differences found between the maximum and minimum proportions in all but four areas were below 0.1. In Greater Hobart, where the largest difference was found, it was only just above 0.2 . Hence, to simplify our estimation method, we decided to use the proportions observed at the end of each five-year period.

\section{Results: Consistent and detailed estimates of international migration to and from}

\section{Australia $^{1}$}

National-scale NOM arrival and departure estimates from 1981 to 2016 are presented in Fig. 3 for populations born in Australia, New Zealand, United Kingdom, China, South-Eastern Europe and Vietnam. Starting at around 40 thousand in 1981, NOM arrivals of persons born in Australia increased with some fluctuations to nearly 65 thousand in 2003 and then decreased to around 51 thousand in 2016. The corresponding departures increased steadily from nearly 30 thousand in 1981 to around 77 thousand in 2001, dropping to 56 thousand in 2009 , and then increased to 68 thousand in 2016. The overall long-run increase in numbers is not surprising given the substantial growth of the Australian population over the study period. The drop in Australia-born NOM departures in the $21^{\text {st }}$ century may be related to economic conditions in destination countries, particularly the Global Financial Crisis.

NOM arrivals of United Kingdom-born persons dropped from 47 thousand in 1981 to 20 thousand in 1984, increased to 37 thousand in 1988, dropped again to around 22 thousand in 1993, and then gradually formed another and even larger peak with a maximum value of

\footnotetext{
${ }^{1}$ The estimated flows are available for download at (AUTHOR REFERENCE TO BE PROVIDED).
} 
53 thousand in 2008. The increase from late 1990s onwards aligns with the introduction of temporary migration visas by the government of the time and the rapid increase in temporary migration to Australia (Hugo 2004). The corresponding departures were more stable, gradually increasing from 13 thousand in 1981 to 24 thousand in 2015.

NOM arrivals of China-born persons, on the other hand, increased exponentially from around one and half thousand persons in 1981 to 73 thousand in 2016 with a brief dip in the flows between 2009 and 2011. This period has witnessed considerable growth in student migration and skilled migration from China, and is related to both changes to migration policy in Australia as well as the economic development of China (Gao 2017). While Chinaborn NOM departures also increased during this period, the numbers were around one half or one third of the corresponding arrival flows.

----- Figure 3 about here -----

To illustrate the state level estimates going back to 1981, NOM arrivals and departures for populations born in the United Kingdom and China, representing established and recent immigrant groups, respectively, are presented in Fig. 4. Here, we see that NOM arrivals of China-born persons was highly concentrated in New South Wales and Victoria throughout the 35 years, whilst NOM arrivals of United Kingdom-born persons was spread more evenly across New South Wales, Victoria, Queensland and Western Australia.

----- Figure 4 about here -----

In the following figures, we highlight some of the NOM arrival patterns resulting from our harmonisation and estimation procedures focusing on selected major cities and regional areas. To start, consider the estimated arrivals from 1981 to 2016 for persons born in Australia, New Zealand, United Kingdom, South-Eastern Europe, Vietnam and China to Sydney, Brisbane, Adelaide and Perth presented in the left panel of Fig. 5. Here, we see that Sydney has experienced a mixture of trends. Arrivals of Australian-born returnees slowly 
increased in the first two decades as the population in general grew, but then dropped and remained at around 15 thousand in recent years. NOM arrival estimates of persons born in the United Kingdom and New Zealand fluctuated at similar levels during the 1980s and 1990s before diverging. NOM arrivals of China-born persons increased from very low levels in the 1980s to the largest flow by far in 2016. The flows of persons born in South-Eastern Europe and Vietnam remained relatively low throughout the 35 years. For arrivals to Brisbane, the most noticeable difference is the large and fluctuating flows from New Zealand, especially during the first and last decades under study. For Adelaide, arrivals in general were much lower than the flows to Sydney and Brisbane. Finally, NOM arrivals to Perth were dominated by persons born in the United Kingdom throughout the 35-year period.

\section{----- Figure 5 about here -----}

Next, consider the estimated NOM arrivals and departures of the six birthplace immigrant populations to four regional areas of Murrumbidgee (New South Wales), Loddon and Goulburn (Victoria), Mackay \& Northern (Queensland) and Darwin (Northern Territory) presented in the left panel of Fig. 6. First, the NOM arrivals and departures are much smaller than those to the major cities. Second, arrival and departure flows of Australia-born persons often represented the largest flow due to their larger population size. Third, departures of Australia-born persons from the four regional areas increased whilst those from the other birthplace groups remained relatively stable (except for Darwin). Fourth, while China-born persons were major contributors to the cities, they were not so for these areas. Finally, arrival flows to Mackay \& Northern and Darwin both experienced considerable fluctuations over time.

----- Figure 6 about here -----

To further illustrate some of the detail available with the estimated NOM flows, in Fig. 7, we present the age compositions of arrivals and departures (standardised to unit area) 
for the two capital city areas of Sydney and Perth. The standardised age profiles allow us to compare the different shapes of migration occurring across the six birthplace groups emphasised in this study. We also include the first year (1981) and last year (2016) in the study to illustrate how the patterns can change over time. As would be expected, the age composition of Australia-born (returning) NOM arrivals included people from a broader range of age groups relative to the overseas-born groups. However, Australia-born NOM departures included a large proportion of children aged 0-9 years, which differed substantially from other birthplace populations. These children are comprised of children born to both Australia-born mothers and overseas-born mothers. The proportion of Australiaborn children aged 0-4 years emigrating remained at around 0.20 from 1981 to 2016.

----- Figure 7 about here -----

New Zealand-born NOM arrivals and departures were concentrated in the young adult age group of 20-24 years in 1981 but over a broader range of ages in 2016 (see Fig. 7). The majority of Vietnam-born arrivals was at the young ages 0-19 years in 1981, while the age pattern of departures was not clear due to sparse data. In 2016, the share of children and teenagers decreased and the age groups 15-19 years and 20-24 years took the major shares of Vietnam-born arrivals. The China-born flows demonstrated a very sharp age profile where $30-35 \%$ of arrivals were at the age group 20-24 years and with around the same proportion in the 25-29 year old age group in the departure flow.

Finally, in Fig. 8, we present some examples of the age profiles of NOM arrivals and departures to two regional areas of Australia in 1981 and 2016: Murrumbidgee and Darwin. Here, we see more variations in the age profiles due to the relatively small sizes of the flows, particularly in the earlier years of the study period. For example, the 1981 departure flow from Darwin comprised only a handful of individuals for the New Zealand-born, United 
Kingdom-born, and South-Eastern Europe-born populations, and there were no Vietnam-born or China-born departures. There were also no Australia-born departures above age 50 years.

----- Figure 8 about here -----

\section{Discussion and conclusion}

In this paper we have described a methodology for estimating detailed immigration and emigration flows for Australian sub-state regions by birthplace, age and sex covering a 35year period from 1981 to 2016 . The methods combine census data, publically available international migration statistics, and international passenger movement data. The dataset of international migration flows will likely prove useful to researchers and policy makers who wish to gain a more complete picture of how international migration affects Australia's regions and influences their demographic evolutions.

As Willekens (1994) argues, methods for combining migration data are needed for overcoming data limitations, harmonising definitions, and understanding data reliability. Although data are often collected for specific purposes, understanding their measurements and relationships with other data types allows researchers to provide both detailed historical understanding, as we have done in this paper, as well as up-to-date estimation of more recent flows. We have focused on international migration flows but, of course, these methods are also relevant for combining different types of internal migration data, normally provided by censuses, surveys or administrative data (Ernsten et al. 2018; Foster et al. 2018; Raymer et al. 2007; Raymer et al. 2011; Smith et al. 2010). With the increasing availability and access to administrative data, along with the increasing costs and difficulties of collecting survey and census data, we believe combining data methods will become even more important in the future --- not only for migration but also for population estimation (Raymer et al. 2015). 
There are several notable contributions provided in this paper. An approach for enhancing existing NOM data in Australia by overcoming the problem of missing detailed flows and inconsistent measurement over time has been developed. The synthetic data set provides a strong platform for analysing the changes that have occurred over time, and for assessing the relative importance of international migration to demographic and social change. Furthermore, through the illustrations of selected major immigrant groups in Australia, a better understanding of how the flows of migration change over time differ across geographic areas has been provided. These contributions may ultimately be useful for refining and improving Australia's immigration policies.

The methodology described in this paper for estimating detailed flows of immigration and emigration is deterministic. To incorporate uncertainty in our estimates, we would need more information about the measurement error in the NOM, OAD and Census data. At present, we do not know enough about the measurement errors present in each of the data sources to form the necessary priors for, say, Bayesian model estimation, as Bryant and Graham (2015) have done for New Zealand. The ideal agency to provide this information is the Australian Bureau of Statistics, who processes and manages the data.

In conclusion, we hope this work will motivate other researchers and analysts to apply methodologies to improve the availability of migration data in their own countries and to propose further methodological advancements, including methods for incorporating measures of uncertainty. More detailed data on migration processes allow investigation of heterogeneity present in the underlying flows and the mechanisms resulting in changes to the levels and compositions of the migrants. Increasingly, we find that governments are less willing to collect new data and instead prefer to make better use of their exisiting administrative data. Methods for combining available data sources are more efficient and less costly. They may also be utilised to identify inadequacies in exisiting data sources, thus 
providing a means to improve data that are made available to the public. In the future, we plan to use these detailed estimates of immigration and emigration to study the sources of demographic change of immigrant groups across both cities and regions in Australia - a country that has undergone a major social and economic transformation in the past 35 years. 


\section{References}

ABS (2014). Australian historical population statistics, 2014. Document no. 3105.0.65.001, Australian Bureau of Statistics, Canberra, http://www.abs.gov.au/AUSSTATS/abs@.nsf/Latestproducts/3105.0.65.001Main\%20 $\underline{\text { Features 12014 } \text { opendocument } \& \text { tabname }=\text { Summary } \& \text { prodno }=3105.0 .65 .001 \& \text { issue }=2}$ 014\&num=\&view.

ABS (2016). Overseas born Aussies highest in over a century. Media Release 03/2016, Australian Bureau of Statistics, Canberra, http://www.abs.gov.au/AUSSTATS/abs@.nsf/Previousproducts/3412.0Media\%20Rel ease12014-15?opendocument \& tabname=Summary \&prodno=3412.0\&issue=2014$\underline{15 \& \text { num }=\& \text { view. }}$.

ABS (2017). Regional population growth, Australia, 2016. Document no. 3218.0, Australian Bureau of Statistics, Canberra, http://www.abs.gov.au/ausstats/abs@.nsf/mf/3218.0. ABS (2018a). Overseas arrivals and departures, Australia: Explanatory notes. Document 3401.0, Australian Bureau of Statistics, Canberra, http://www.abs.gov.au/AUSSTATS/abs@.nsf/Lookup/3401.0Explanatory\%20Notes1 May\%202018?OpenDocument.

ABS (2018b). Overseas arrivals and departures, Australia: Data quality issues appendix.

Document 3401.0, Australian Bureau of Statistics, Canberra, http://www.abs.gov.au/AUSSTATS/abs@.nsf/Previousproducts/3401.0Appendix2Ma y\%202018? opendocument \&tabname $=$ Notes $\&$ prodno $=3401.0 \&$ issue $=$ May $\% 202018 \&$ $\underline{\text { num }=\& \text { view. }}$

ABS (2018c). Migration, Australia, 2016-17. Document 3412.0, Australian Bureau of Statistics, Canberra, 
http://www.abs.gov.au/AUSSTATS/abs@.nsf/Lookup/3412.0Explanatory\%20Notes1

2016-17?OpenDocument.

ABS (2018d). Improvements to the estimation of net overseas migration. Document

3412.0.55.004, Australian Bureau of Statistics, Canberra,

http://www.abs.gov.au/AUSSTATS/abs@.nsf/Lookup/3412.0.55.004Glossary1Mar\%

202018?OpenDocument.

ABS (2018e). Australian Statistical Geography Standard (ASGS). Australian Bureau of Statistics, Canberra,

http://www.abs.gov.au/websitedbs/D3310114.nsf/home/Australian+Statistical+Geogr

aphy+Standard+(ASGS).

Ahmed, B., \& Robinson, J. G. (1994). Estimates of emigration of the foreign-born population: 1980-1990. Technical Working Paper No. 9, Population Division, U.S. Bureau of the Census, Washington DC.

Blake, M., Bell, M., \& Rees, P. (2000). Creating a temporally consistent spatial framework for the analysis of inter-regional migration in Australia. International Journal of Population Geography, 6, 155-174.

Boden, P., \& Rees, P. (2010). Using administrative data to improve the estimation of immigration to local areas in England. Journal of the Royal Statistical Society, Series A, 173(4), 707-731.

Castles, S., De Haas, H., \& Miller, M. J. (2014). The age of migration: International population movements in the modern world, $5^{\text {th }}$ Edition. Houndmills: Palgrave Macmillan.

Charles-Edwards, E., Wilson, T., \& Sander N. (2015) Visualizing Australian internal and international migration flows. Regional Studies, Regional Science 2(1): 431-433. 
Ernsten, A., McCollum, D., Feng, Z., Everington, D., \& Huang, Z. (2018). Using linked administrative and census data for migration research. Population Studies, 72(3), 357367.

Foster, T. B., Ellis, M., \& Fiorio, L. (2018). Foreign-born and native-born migration in the U.S.: Evidence from linked IRS administrative and census survey records. Journal of Population Research, 35(4), 467-498.

Gao, J. (2017) Rediscovering the New Gold Mountain: Chinese Immigration to Australia Since the Mid-1980s. In Zhou M (ed.) Contemporary Chinese Diasporas. Singapore: Palgrave Macmillan; pp. 209-231.

Hugo, G. (1986). Australia's changing population: Trends and implications. Melbourne: Oxford University Press.

Hugo, G. (2004). A new paradigm of international migration: implications for migration policy and planning in Australia. Research Paper No. 10 2003-04, Parliamentary Library, Canberra.

Hugo, G. (2008). Immigrant settlement outside of Australia's capital cities. Population, Space and Place, 14, 553-571.

Jupp, J. (1995). From 'White Australia' to 'part of Asia': Recent shifts in Australian immigration policy towards the region. International Migration Review, 29(1), 207228.

Jupp, J., Ed. (2001). The Australian people: An encyclopedia of the nation, its people and their origins. Cambridge: Cambridge University Press.

Khoo, S.-E. (2002). Immigration issues in Australia. In G. A. Carmichael \& A. Dharmalingam (Eds.), Joint Special Issue of Journal of Population Research and NZ Population Review (pp. 67-78). 
Khoo, S.-E. (2003). A greater diversity of origins. In S.-E. Khoo S-E \& P. McDonald (Eds.), The transformation of Australia's population: 1970-2030 (pp. 158-184). Sydney: University of New South Wales Press.

Khoo, S.-E., Hugo, G., \& McDonald, P. (2011). Skilled migration from Europe to Australia. Population, Space and Place, 17(5), 550-566.

Markus, A., Jupp, J., \& McDonald, P. (2009). Australia's immigration revolution. Sydney: Allen \& Unwin.

Nicholson, B. (1990). The hidden component in census-derived migration data: Assessing its size and distribution. Demography, 27(1), 111-119.

ONS (2018). Methodology: Local area migration indicators Suite QMI. Office for National Statistics, Titchfield, https://www.ons.gov.uk/peoplepopulationandcommunity/populationandmigration/inte $\underline{\text { rnationalmigration/methodologies/localareamigrationindicatorssuiteqmi. }}$

Parliament of Australia (2010). Australia's migration program. Parliament of Australia, Canberra, https://www.aph.gov.au/About_Parliament/Parliamentary_Departments/Parliamentary _Library/pubs/BN/1011/AustMigration.

Price, C. A. (1998). Postwar immigration 1947-98. Journal of the Australian Population Association, 15(2), 115-129.

Raymer, J., Abel, G., \& Smith, P. W. F. (2007). Combining census and registration data to estimate detailed elderly migration flows in England and Wales. Journal of the Royal Statistical Society, Series A, 170(4), 891-908.

Raymer, J., \& Baffour, B. (2018). Subsequent migration of immigrants within Australia, 1981-2016. Population Research and Policy Review, 37(6), 1053-1077. 
Raymer, J., Rees, P., \& Blake, A. (2015). Frameworks for guiding the development and improvement of population statistics in the United Kingdom. Journal of Official Statistics, 31(4), 699-722.

Raymer, J., Shi, Y., Guan, Q., Baffour, B., \& Wilson, T. (2018). The sources and diversity of immigrant population change in Australia, 1981-2011. Demography, 55(5), 17771802.

Raymer, J., Smith, P. W. F., \& Giulietti, C. (2011). Combining census and registration data to analyse ethnic migration patterns in England from 1991 to 2007. Population, Space and Place, 17, 73-88.

Rees, P. H. (1977). The measurement of migration, from census data and other sources. Environment and Planning A: Economy and Space, 9(3), 247-272.

Rees, P. (1985). Does it really matter which migration data you use in a population model? In P. White and G. Van der Knaap (Eds.), Contemporary studies of migration (pp. 5577). Norwich: Geobooks.

Rees, P., \& Willekens, F. J. (1986). Data and accounts. In A. Rogers and F. J. Willekens (Eds.), Migration and settlement: A multiregional comparative study (pp. 19-58). Dordrecht: D. Reidel.

Rogers, A., Raymer, J., \& Newbold, K. B. (2003). Reconciling and translating migration data collected over time intervals of differing widths. The Annals of Regional Science, 37, $581-601$.

Rogers, A., \& Raymer, J. (1999). Estimating the regional migration patterns of the foreignborn population in the United States: 1950-1990. Mathematical Population Studies, 7(3), 181-216.

Rogerson, P. A. (1990). Migration analysis using data with time intervals of differing widths. Papers of the Regional Science Association, 68, 97-106. 
Smith, P. W. F., Raymer, J., \& Giulietti, C. (2010). Combining available migration data in England to study economic activity flows over time. Journal of the Royal Statistical Society, Series A, 173(4), 733-753.

Temple, J. B., \& McDonald, P. F. (2018). Australian migration propensities by visa class: An analysis of linked administrative data. Journal of Population Research, 35(4), 399416.

Van Hook, J., \& Zhang, W. (2011). Who stays? Who goes? Selective emigration among the foreign-born. Population Research and Policy Review, 30(1), 1-24.

Warren, R., \& Kraly, E. P. (1985). The elusive exodus: Emigration from the United States. Population Trends and Public Policy Occasional Paper No. 8, Population Reference Bureau, Washington, DC.

Warren, R., \& Peck, J. M. (1980). Foreign-born emigration from the United States: 19601970. Demography, 17, 71-84.

White, M. J. (2016). Introduction: Contemporary insights on migration and population distribution. In M.J. White (Ed.), International handbook of migration and population distribution (pp. 1-8). Dordrecht: Springer.

Willekens, F. (1994). Monitoring international migration flows in Europe: Towards a statistical data base combining data from different sources. European Journal of Population, 10, 1-42.

Wilson, T. (2017). Methods for estimating sub-state international migration: The case of Australia. Spatial Demography, 5, 171-192.

Wilson, T., \& Charles-Edwards, E. (2017) The regional pattern of Australia's largest overseas-born populations (Regional Graphic). Regional Studies, 4(1), 227-231.

Wilson, T., \& Raymer, J. (2017). The changing shape of Australia's overseas-born population. Population \& Societies, 545, 1-4. 
Table 1 Summary of data sources

\begin{tabular}{|c|c|c|c|c|c|c|c|}
\hline Data source & Period & Age & Sex & Birthplace & Geography & $\begin{array}{l}\text { Immigration } \\
\text { / emigration }\end{array}$ & $\begin{array}{c}\text { Migration } \\
\text { concept }\end{array}$ \\
\hline \multirow[t]{2}{*}{$\begin{array}{l}\text { Net Overseas } \\
\text { Migration (NOM) }\end{array}$} & $\begin{array}{l}\text { Single } \\
\text { calendar } \\
\text { years } \\
2004-2016\end{array}$ & $\sqrt{ }$ & $\sqrt{ }$ & $\sqrt{ }$ & State level & Both & event \\
\hline & $\begin{array}{l}\text { Single } \\
\text { calendar } \\
\text { years } \\
1981-2003\end{array}$ & $\sqrt{ }$ & $\sqrt{ }$ & & State level & Both & event \\
\hline $\begin{array}{l}\text { Overseas Arrivals } \\
\text { and Departures } \\
\text { (OAD) }\end{array}$ & $\begin{array}{l}\text { Single } \\
\text { calendar } \\
\text { years } \\
1981-2013\end{array}$ & $\sqrt{ }$ & $\sqrt{ }$ & $\sqrt{ }$ & State level & Both & event \\
\hline Census & $\begin{array}{l}\text { Censal } \\
\text { years 1981, } \\
1986, \\
1991, \\
1996, \\
2001, \\
2006, \\
2011,2016\end{array}$ & $\sqrt{ }$ & $\sqrt{ }$ & $\sqrt{ }$ & $\begin{array}{c}\text { Sub-state } \\
\text { level }\end{array}$ & $\begin{array}{l}\text { Immigration } \\
\text { only }\end{array}$ & transition \\
\hline
\end{tabular}



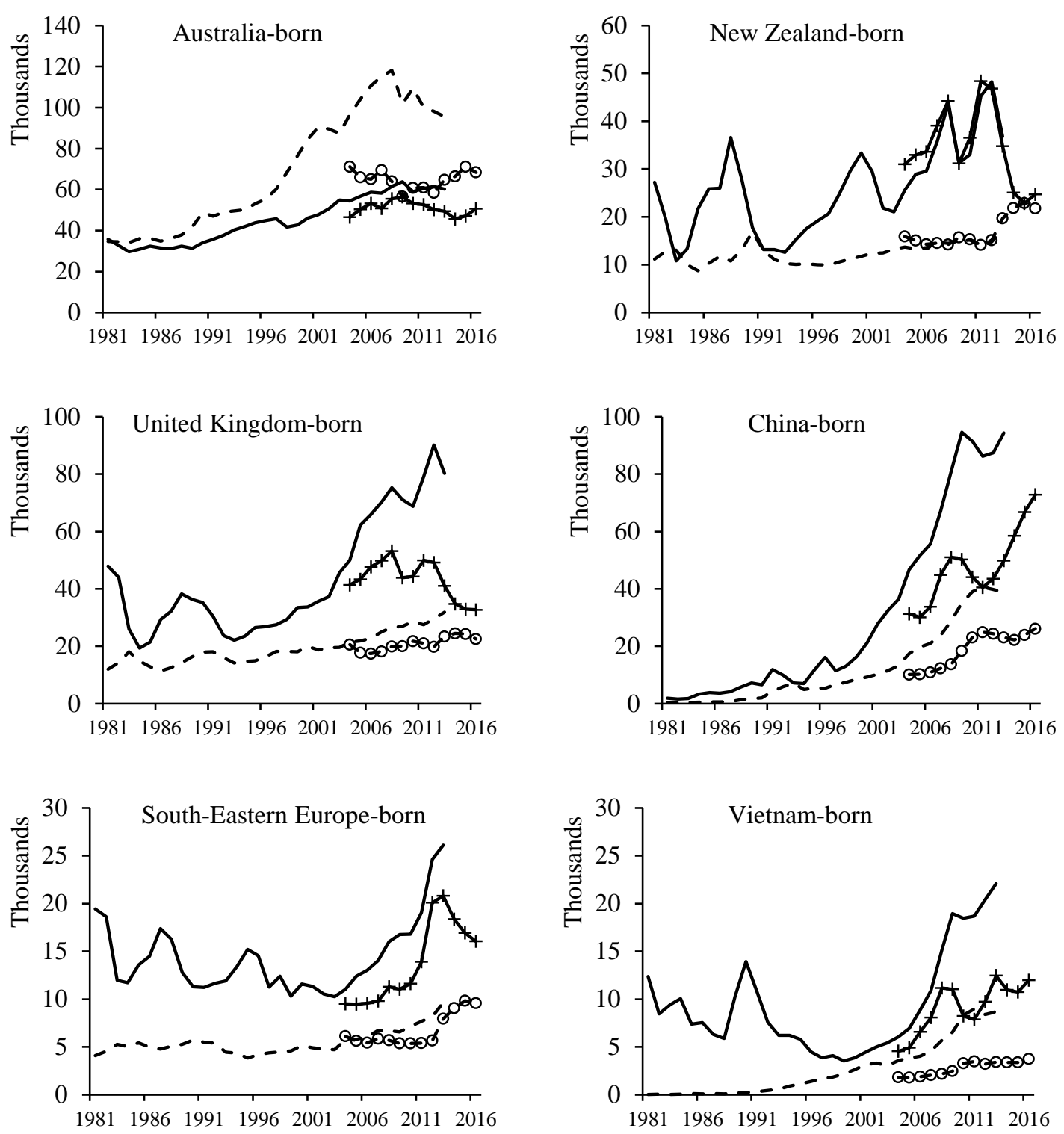

OAD arrivals

OAD departures $\quad$ - - NOM arrivals

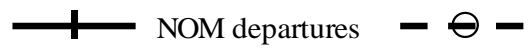

Fig. 1 Comparison between observed OAD and NOM arrivals and departures for selected birthplace groups, 1981-2016. Note: vertical scales vary between graphs. Source: Australian Bureau of Statistics. 
A. Ratios of NOM to OAD arrivals

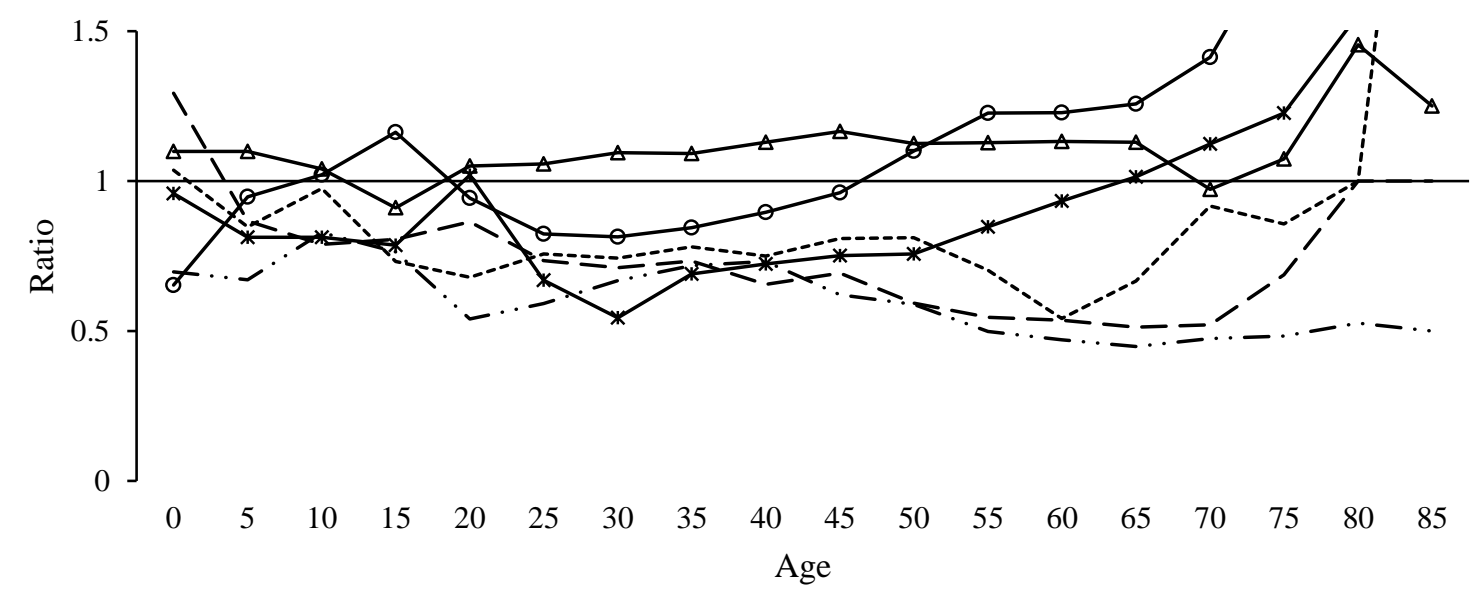

B. Ratios of NOM to OAD departures

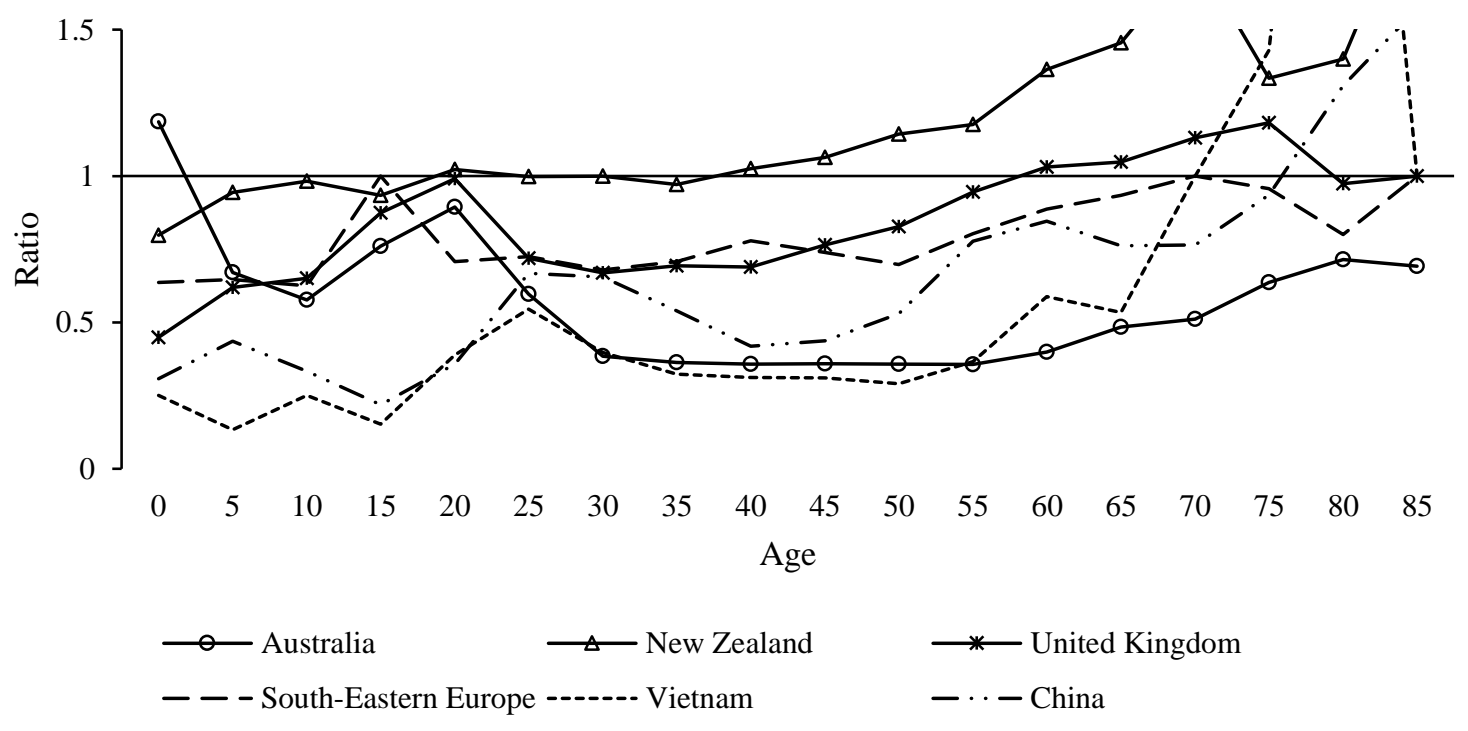

Fig. 2 Age-specific ratios of NOM to OAD arrivals and departures for females born in selected countries, 2004-2008. Note: Observed ratios above 1.5 are excluded from this graph for presentation purposes. 

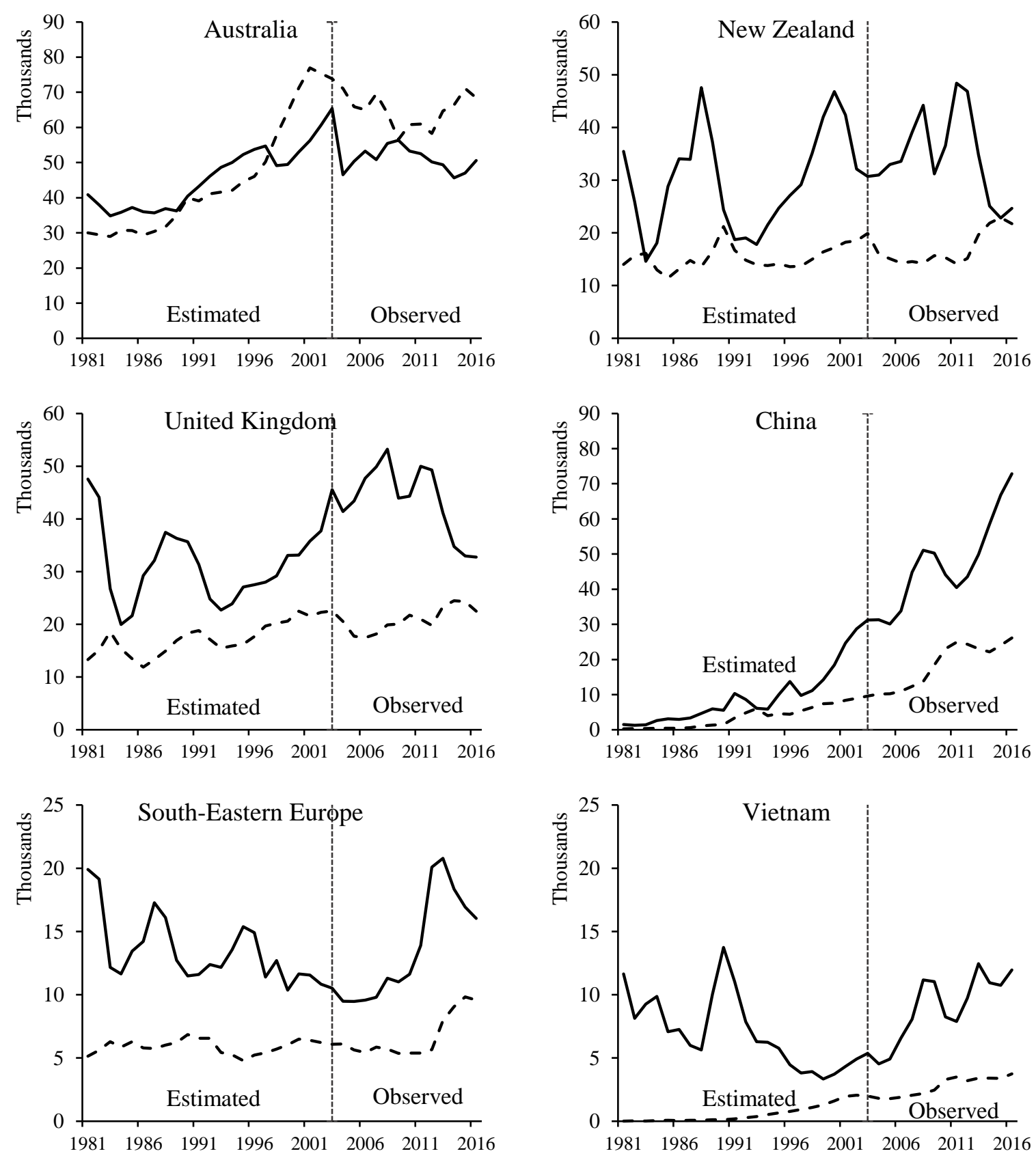

\section{Arrivals}

Departures - - - -

Fig. 3 Estimated and observed NOM arrivals and departures for persons born in Australia, New Zealand, United Kingdom, China, South-Eastern Europe and Vietnam, 1981-2016. Note: vertical scales vary between graphs. 

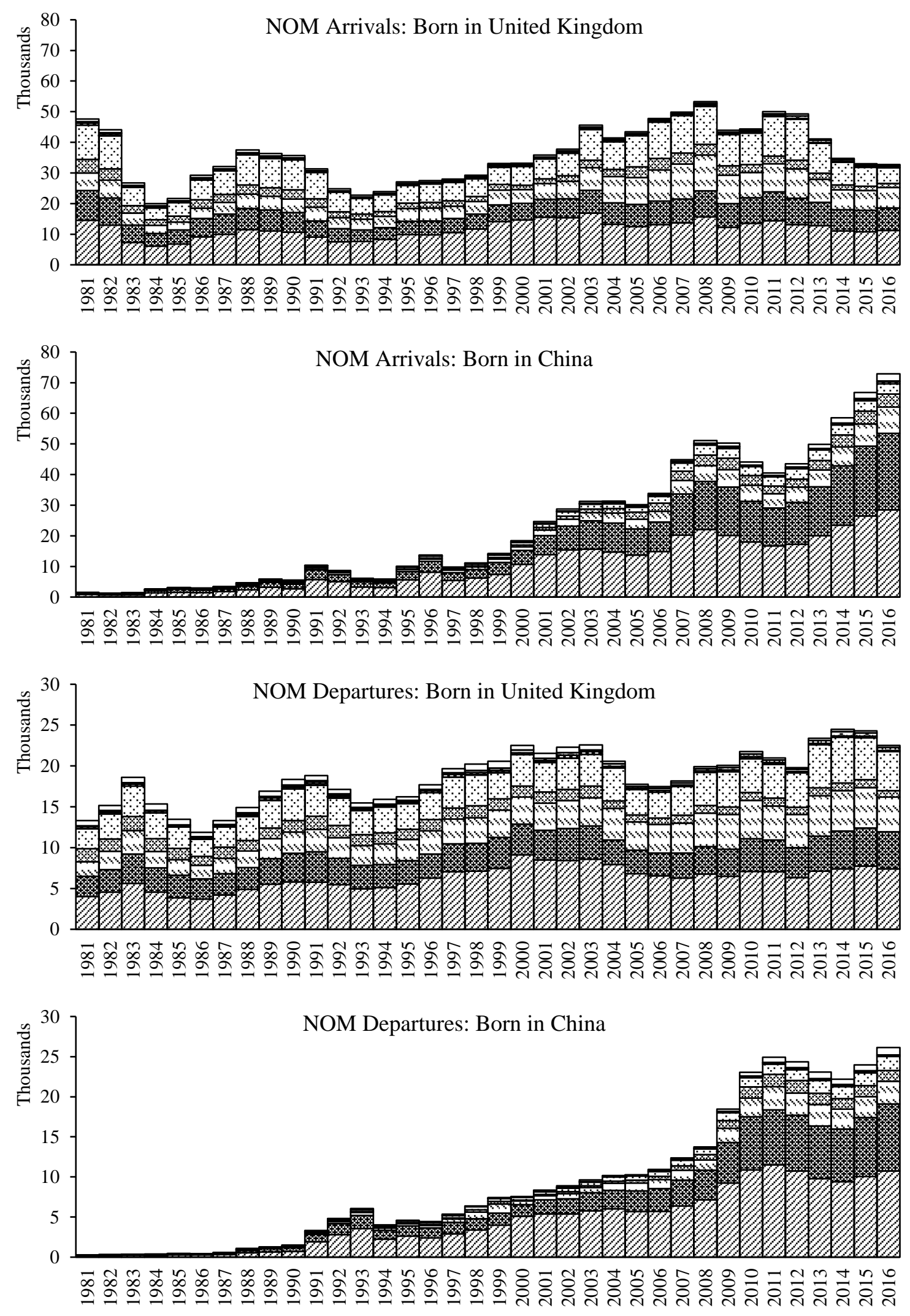

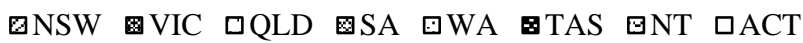

Fig. 4 Estimated NOM arrivals and departures by state and territory for persons born in the United Kingdom and China, 1981-2016. Note: vertical scales vary between graphs. Source: Australian Bureau of Statistics. 

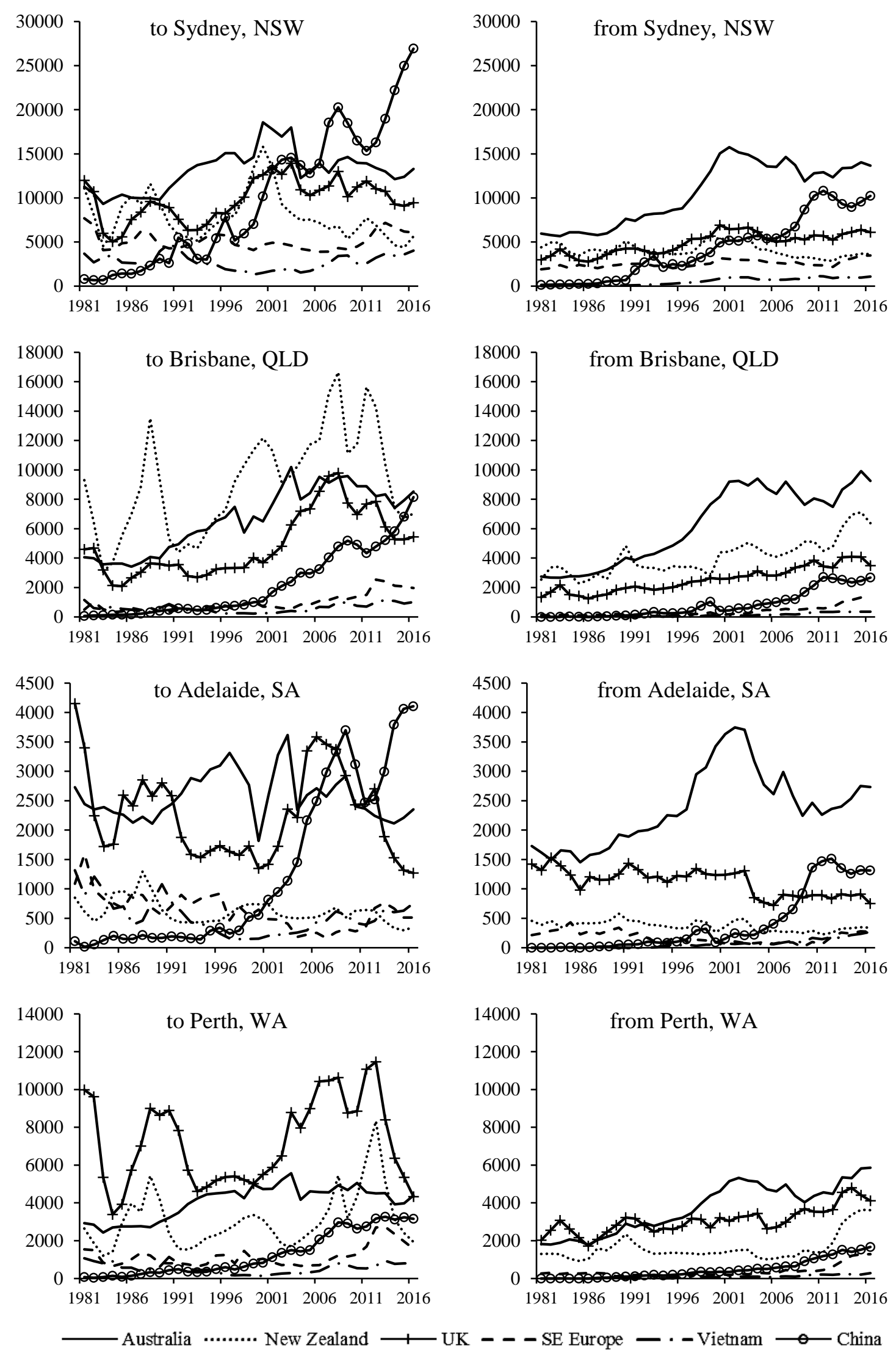

Fig. 5 Estimated NOM arrivals and departures by birthplace for selected major cities, 19812016. Note: vertical scales vary between graphs. 

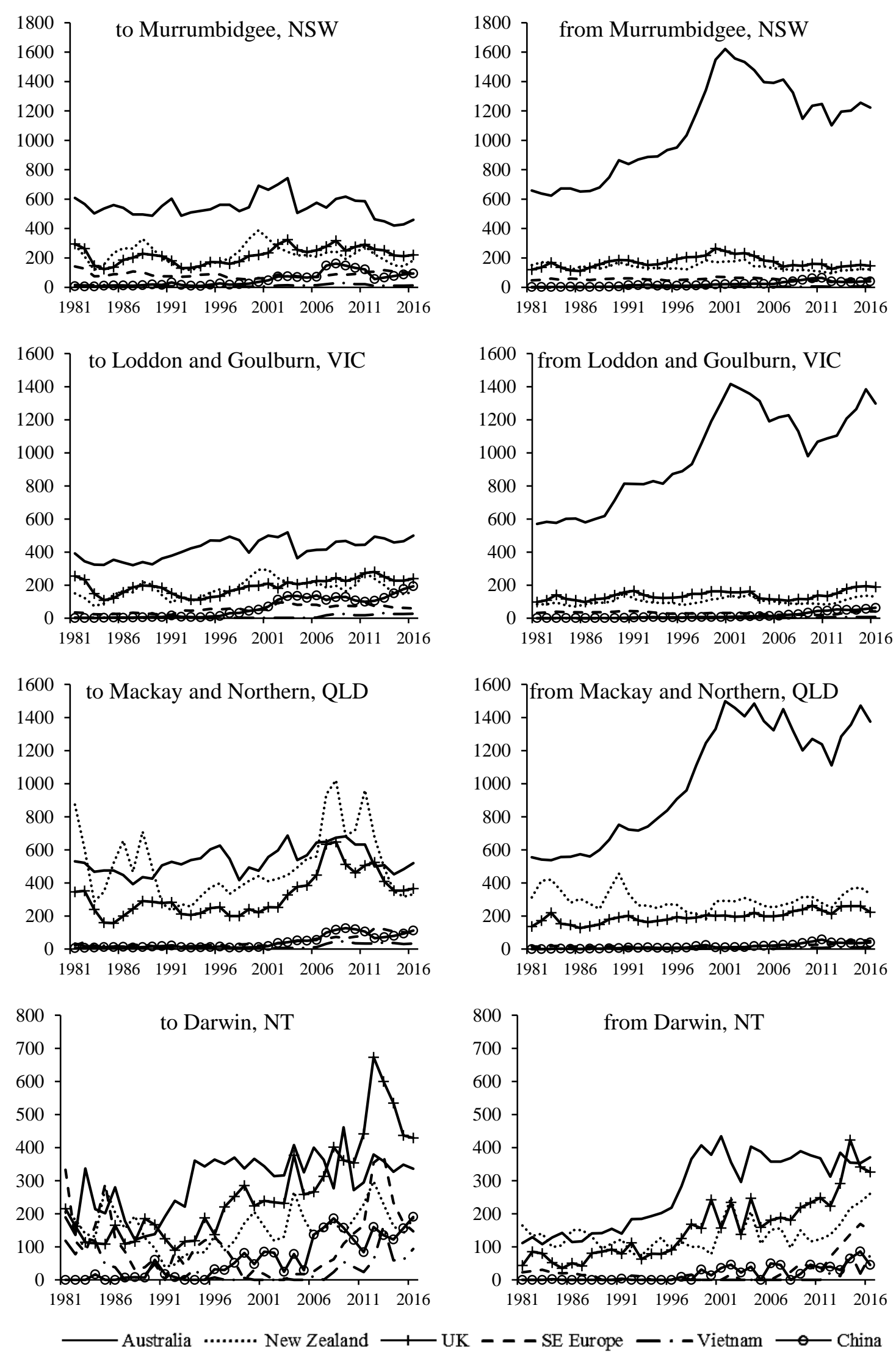

Fig. 6 Estimated NOM arrivals and departures in selected regional areas by birthplace, 19812016. Note: vertical scales vary between graphs. 

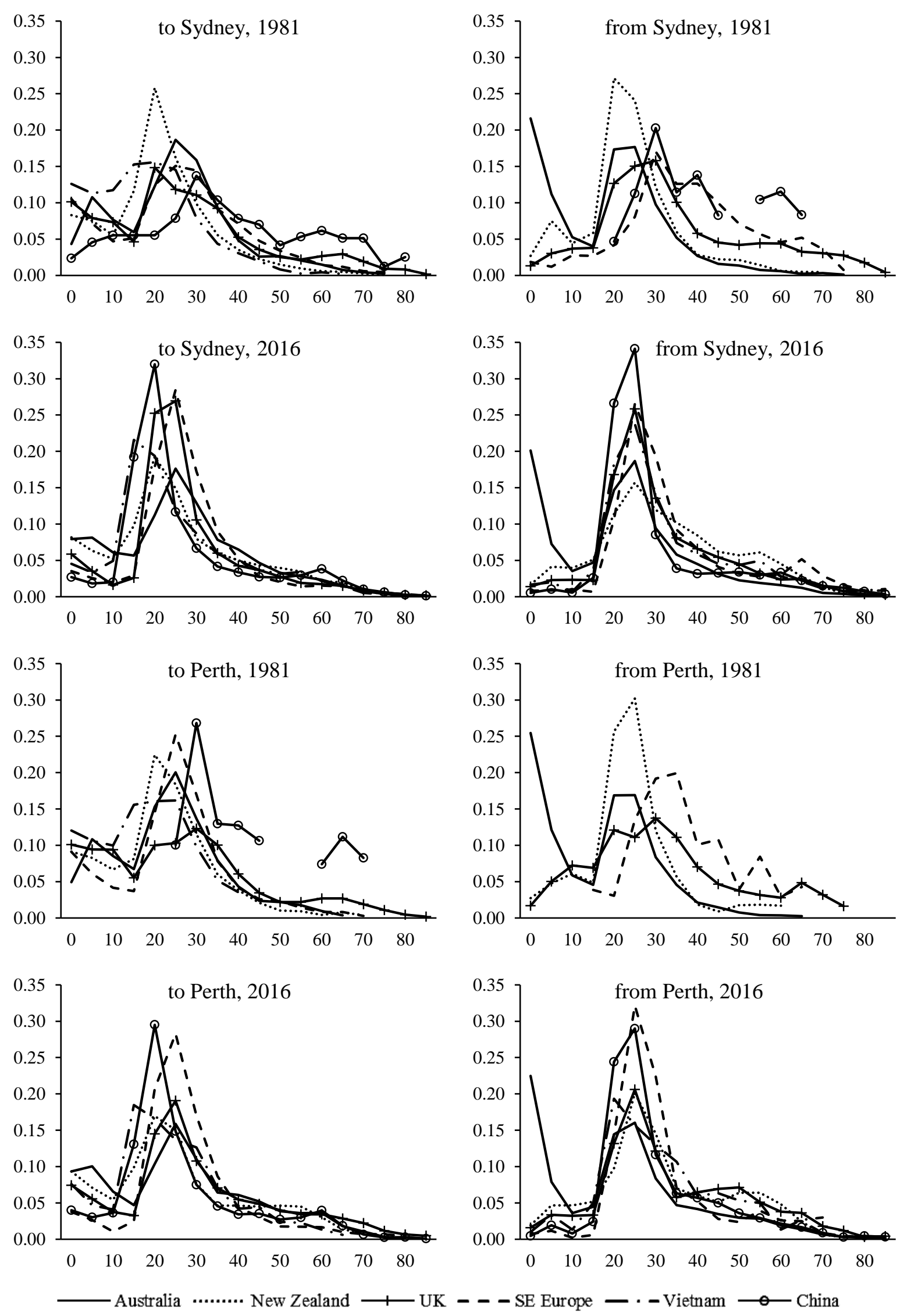

Fig. 7 Estimated age profiles of birthplace-specific NOM arrivals and departures for Sydney and Perth, 1981 and 2016 

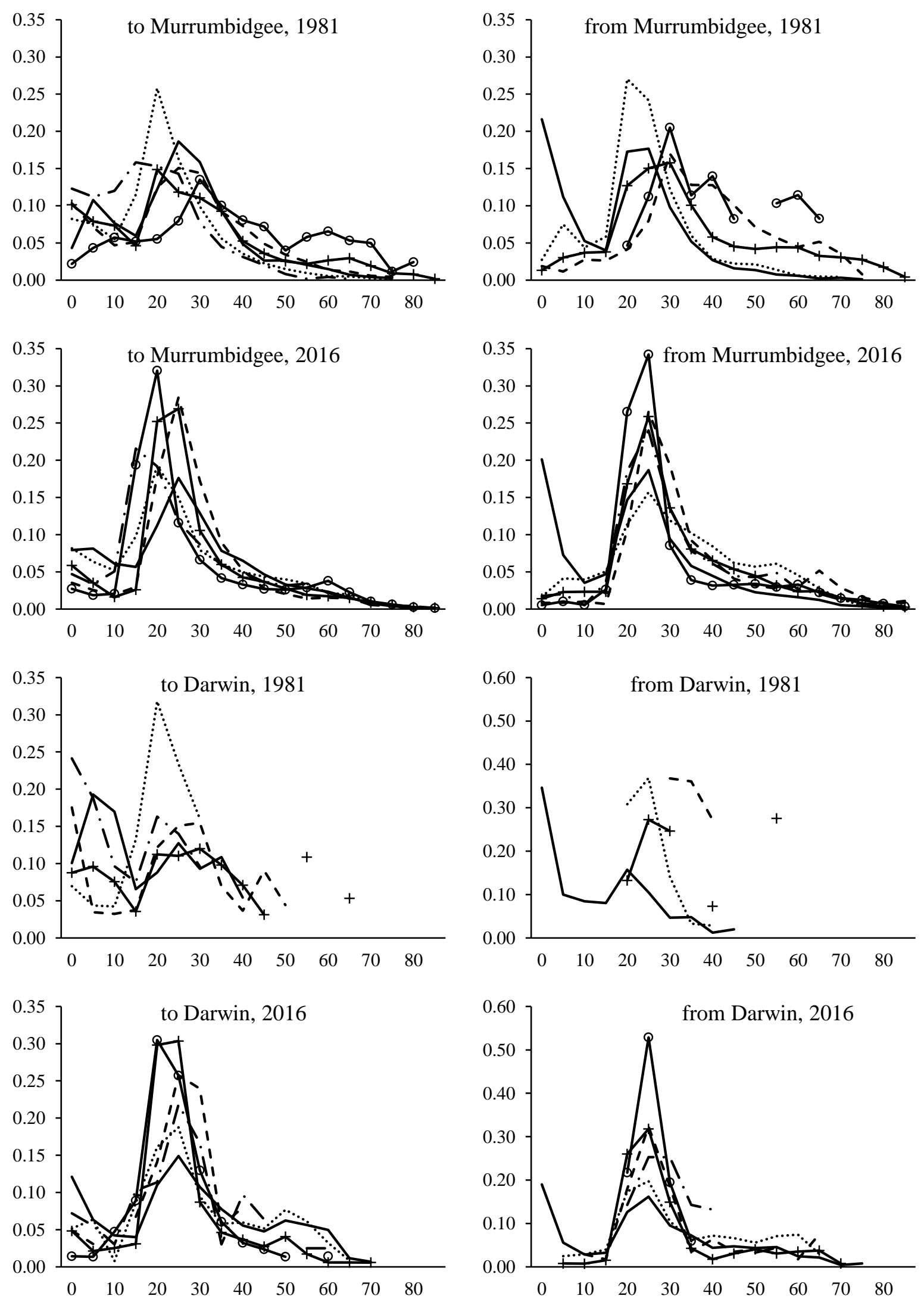
— Australia ........ New Zealand —— UK - - - SE Europe — - - Vietnam — China

Fig. 8 Estimated age profiles of birthplace-specific NOM arrivals and departures for Murrumbidgee and Darwin, 1981 and 2016. Note: vertical scales vary between graphs. 
Appendix 1A Populations in Australia by country or region of birth, 2016

\begin{tabular}{|c|c|c|c|}
\hline & Birthplace & Population & $\begin{array}{c}\% \text { Total } \\
\text { Foreign- } \\
\text { Born }\end{array}$ \\
\hline 1 & Australia & $17,254,110$ & \\
\hline 2 & New Zealand & 607,230 & 8.8 \\
\hline 3 & Other Oceania and Antarctica & 165,370 & 2.4 \\
\hline 4 & United Kingdom & $1,197,970$ & 17.4 \\
\hline 5 & Other North-West Europe & 414,080 & 6.0 \\
\hline 6 & South-East Europe & 788,820 & 11.5 \\
\hline 7 & North Africa and the Middle East & 410,320 & 6.0 \\
\hline 8 & Vietnam & 236,750 & 3.4 \\
\hline 9 & Philippines & 246,430 & 3.6 \\
\hline 10 & Malaysia & 166,150 & 2.4 \\
\hline 11 & Indonesia & 83,780 & 1.2 \\
\hline 12 & Other South-East Asia & 240,000 & 3.5 \\
\hline 13 & China (excludes SARs, Taiwan) & 526,040 & 7.7 \\
\hline 14 & Other North-East Asia & 326,900 & 4.8 \\
\hline 15 & India & 468,830 & 6.8 \\
\hline 16 & Other Southern and Central Asia & 334,400 & 4.9 \\
\hline 17 & North America & 181,500 & 2.6 \\
\hline 18 & South America & 123,660 & 1.8 \\
\hline 19 & Sub-Saharan Africa & 354,560 & 5.2 \\
\hline
\end{tabular}

Source: Australian Bureau of Statistics, Estimated Resident Populations 
Appendix 1B Map of consistent geographic areas between 1981 and 2016 census years for Australia

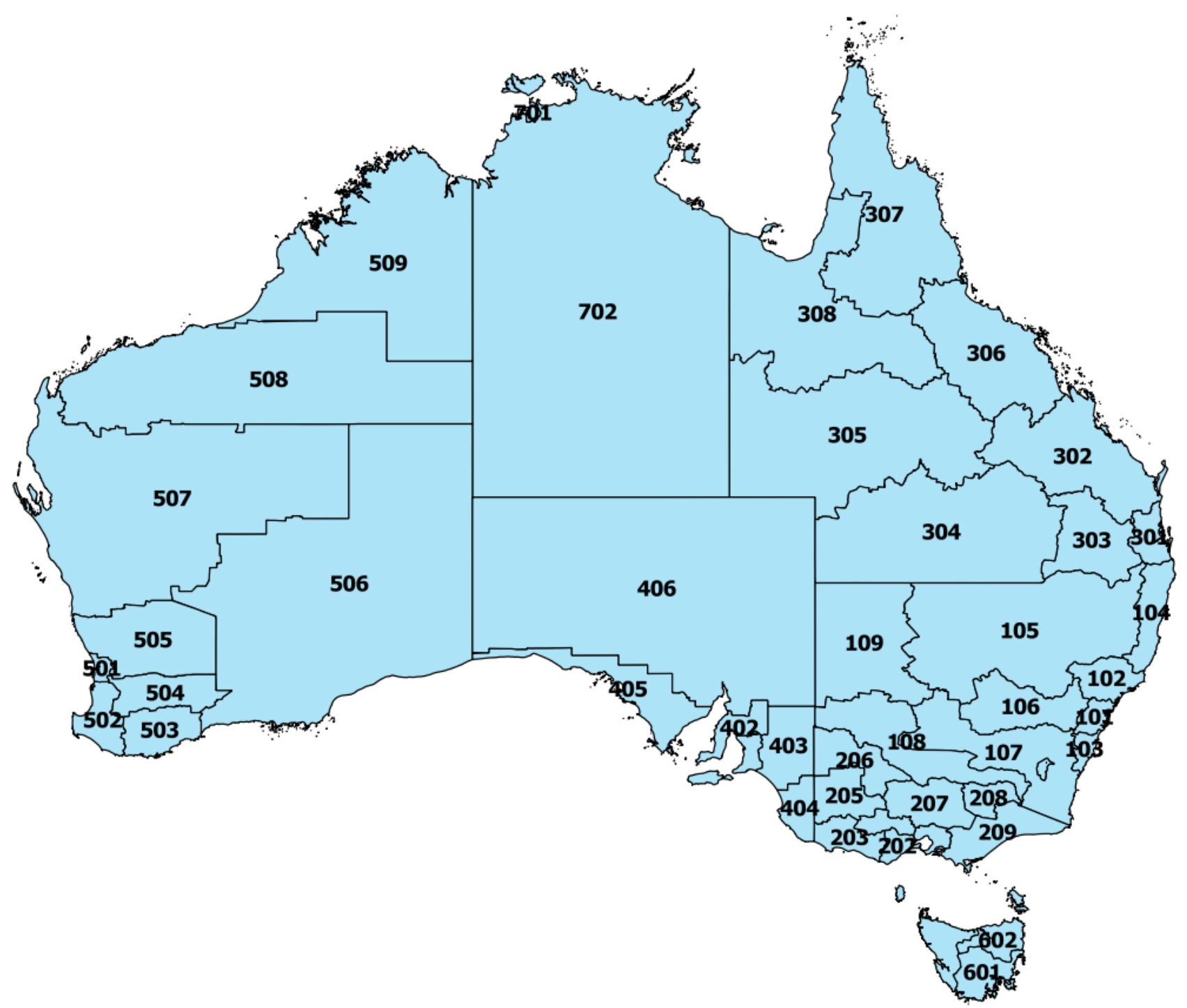


Appendix 1C List of Australian geographic area codes and area names

\begin{tabular}{|c|c|c|c|c|c|}
\hline \multicolumn{3}{|c|}{ Area } & \multicolumn{3}{|c|}{ Area } \\
\hline State & Code & Area Name & State & Code & Area Name \\
\hline \multirow{9}{*}{$\begin{array}{l}\text { New South } \\
\text { Wales } \\
\text { (NSW) }\end{array}$} & 101 & Sydney & \multirow{9}{*}{$\begin{array}{c}\text { Western } \\
\text { Australia } \\
\text { (WA) }\end{array}$} & 501 & Perth \\
\hline & 102 & Hunter & & 502 & South West \\
\hline & 103 & Illawarra & & 503 & Lower Southern WA \\
\hline & 104 & Mid-North Coast & & 504 & Upper Southern WA \\
\hline & 105 & North West NSW & & 505 & Midlands \\
\hline & 106 & Central West NSW & & 506 & South Eastern WA \\
\hline & 107 & Murrumbidgee & & 507 & Central WA \\
\hline & 108 & Murray & & 508 & Pilbara \\
\hline & 109 & West NSW & & 509 & Kimberley \\
\hline \multirow{9}{*}{$\begin{array}{l}\text { Victoria } \\
\text { (VIC) }\end{array}$} & 201 & Melbourne & \multirow{3}{*}{$\begin{array}{c}\text { Tasmania } \\
\text { (TAS) }\end{array}$} & 601 & Greater Hobart \\
\hline & 202 & Barwon & & 602 & Northern Tasmania \\
\hline & 203 & Western District & & 603 & Mersey-Lyell \\
\hline & 204 & Central Highlands & \multirow{6}{*}{$\begin{array}{c}\text { Northern } \\
\text { Territory } \\
\text { (NT) } \\
\text { Australian } \\
\text { Capital } \\
\text { Territory } \\
\text { (ACT) }\end{array}$} & 701 & Darwin \\
\hline & 205 & Wimmera & & 702 & Northern Territory \\
\hline & 206 & Mallee & & 801 & Canberra \\
\hline & 207 & Loddon \& Goulburn & & & \\
\hline & 208 & Ovens-Murray & & & \\
\hline & 209 & Gippsland & & & \\
\hline \multirow{8}{*}{$\begin{array}{l}\text { Queensland } \\
\text { (QLD) }\end{array}$} & 301 & Brisbane & & & \\
\hline & 302 & Wide Bay-Burnett \& Fitzroy & & & \\
\hline & 303 & Darling Downs & & & \\
\hline & 304 & South West Queensland & & & \\
\hline & 305 & Central West Queensland & & & \\
\hline & 306 & Mackay \& Northern & & & \\
\hline & 307 & Far North & & & \\
\hline & 308 & North West & & & \\
\hline \multirow{6}{*}{$\begin{array}{l}\text { South } \\
\text { Australia } \\
\text { (SA) }\end{array}$} & 401 & Adelaide & & & \\
\hline & 402 & Yorke \& Lower North & & & \\
\hline & 403 & Murray Lands & & & \\
\hline & 404 & South East & & & \\
\hline & 405 & Eyre & & & \\
\hline & 406 & Northern SA & & & \\
\hline
\end{tabular}


Appendix 2A Average NOM to OAD immigration ratios by age and state or territory for females born in selected birthplaces, 2004-2008
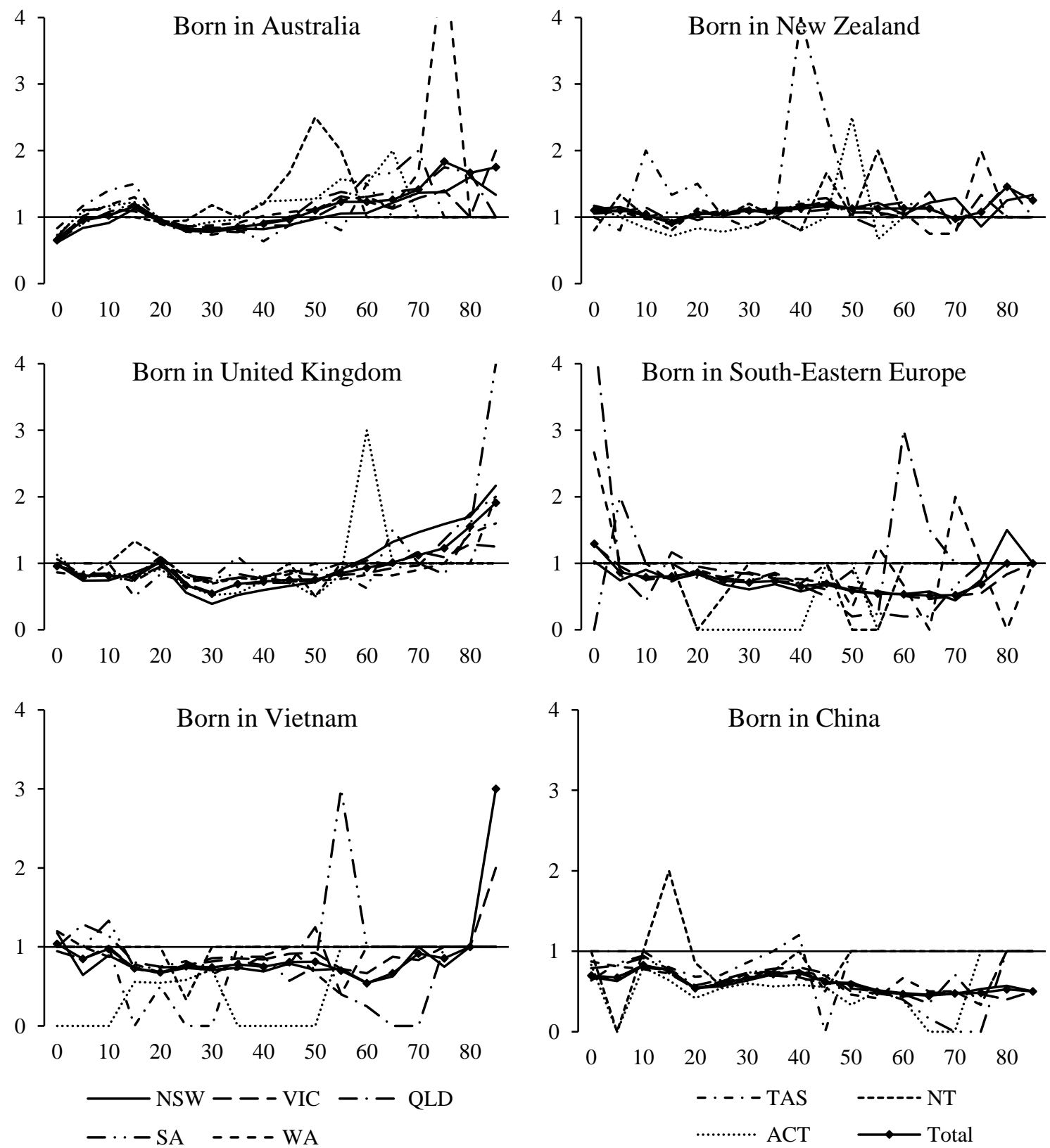
Appendix 2B Average NOM to OAD emigration ratios by age and state or territory for females born in selected birthplaces, 2004-2008
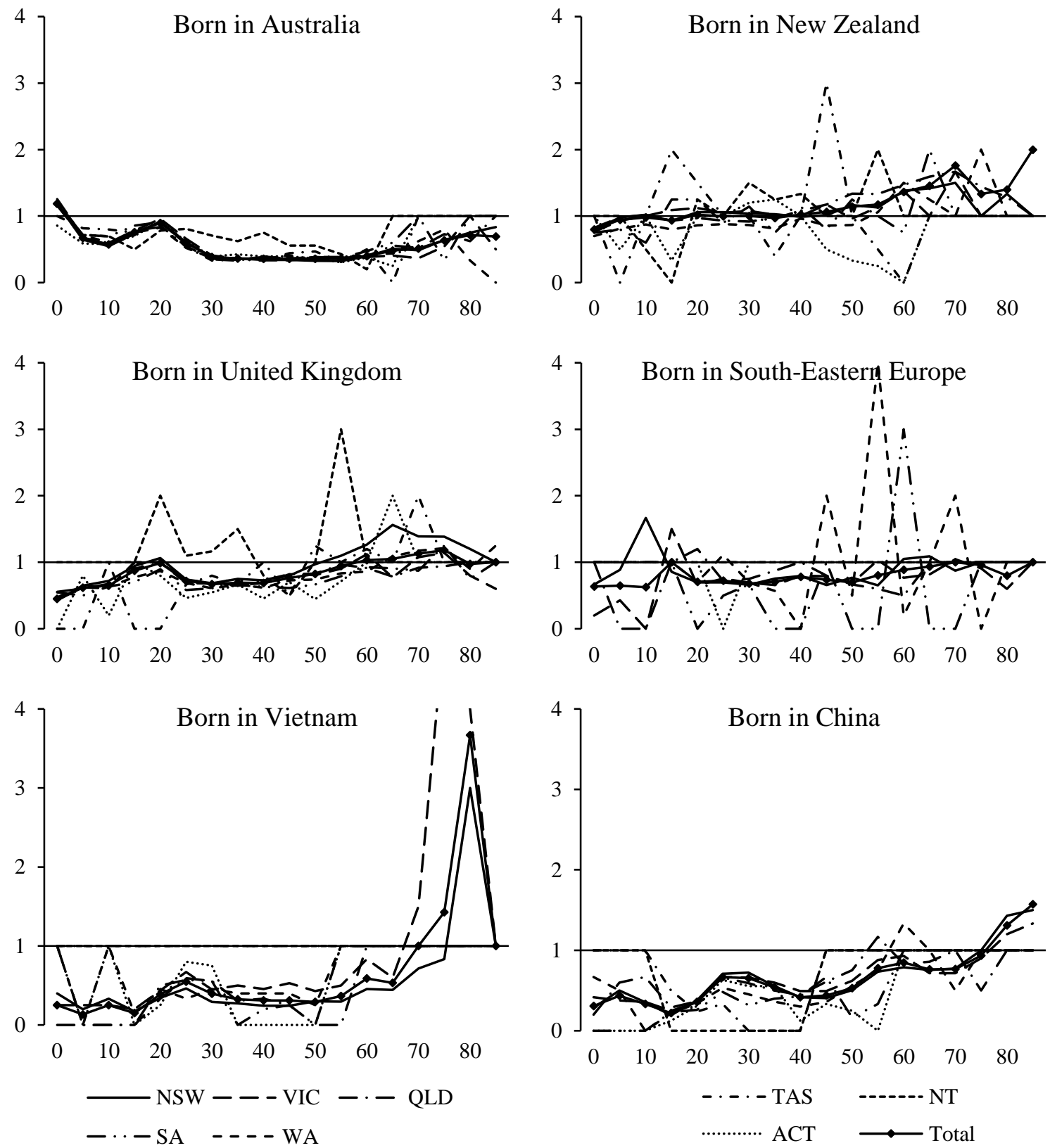
Appendix 3 Proportions used to distribute state-level NOM arrivals $(I)$ and departures $(E)$ to sub-state regions in Australia: China-born females, 1981-1986, 1991-1996, 2001-2006 and 2011-2016

\begin{tabular}{|c|c|c|c|c|c|c|c|c|c|}
\hline \multirow[t]{2}{*}{ State } & \multirow[t]{2}{*}{ Area Code } & \multicolumn{2}{|c|}{$1981-86$} & \multicolumn{2}{|c|}{$1991-96$} & \multicolumn{2}{|c|}{$2001-06$} & \multicolumn{2}{|c|}{$2011-16$} \\
\hline & & I & $\mathrm{E}$ & I & $\mathrm{E}$ & I & $\mathrm{E}$ & I & $\mathrm{E}$ \\
\hline \multirow[t]{9}{*}{ NSW } & 101 & 0.9306 & 0.9025 & 0.9668 & 0.9594 & 0.9411 & 0.9609 & 0.9529 & 0.9572 \\
\hline & 102 & 0.0196 & 0.0245 & 0.0090 & 0.0121 & 0.0121 & 0.0088 & 0.0151 & 0.0142 \\
\hline & 103 & 0.0163 & 0.0154 & 0.0112 & 0.0109 & 0.0297 & 0.0166 & 0.0203 & 0.0158 \\
\hline & 104 & 0.0060 & 0.0136 & 0.0028 & 0.0047 & 0.0059 & 0.0040 & 0.0035 & 0.0033 \\
\hline & 105 & 0.0090 & 0.0119 & 0.0048 & 0.0049 & 0.0045 & 0.0034 & 0.0032 & 0.0036 \\
\hline & 106 & 0.0040 & 0.0147 & 0.0005 & 0.0023 & 0.0012 & 0.0015 & 0.0016 & 0.0015 \\
\hline & 107 & 0.0106 & 0.0144 & 0.0030 & 0.0045 & 0.0050 & 0.0039 & 0.0030 & 0.0037 \\
\hline & 108 & 0.0040 & 0.0030 & 0.0011 & 0.0009 & 0.0005 & 0.0008 & 0.0004 & 0.0008 \\
\hline & 109 & 0.0000 & 0.0000 & 0.0008 & 0.0002 & 0.0000 & 0.0000 & 0.0000 & 0.0000 \\
\hline \multirow[t]{9}{*}{ VIC } & 201 & 0.9764 & 0.9340 & 0.9838 & 0.9806 & 0.9623 & 0.9716 & 0.9733 & 0.9714 \\
\hline & 202 & 0.0000 & 0.0369 & 0.0062 & 0.0084 & 0.0082 & 0.0075 & 0.0082 & 0.0089 \\
\hline & 203 & 0.0000 & 0.0018 & 0.0006 & 0.0004 & 0.0008 & 0.0008 & 0.0015 & 0.0015 \\
\hline & 204 & 0.0118 & 0.0073 & 0.0018 & 0.0019 & 0.0081 & 0.0049 & 0.0050 & 0.0052 \\
\hline & 205 & 0.0000 & 0.0000 & 0.0000 & 0.0000 & 0.0013 & 0.0008 & 0.0003 & 0.0005 \\
\hline & 206 & 0.0000 & 0.0000 & 0.0000 & 0.0008 & 0.0007 & 0.0007 & 0.0013 & 0.0014 \\
\hline & 207 & 0.0059 & 0.0127 & 0.0030 & 0.0026 & 0.0134 & 0.0082 & 0.0068 & 0.0070 \\
\hline & 208 & 0.0000 & 0.0018 & 0.0000 & 0.0000 & 0.0008 & 0.0015 & 0.0008 & 0.0010 \\
\hline & 209 & 0.0059 & 0.0054 & 0.0046 & 0.0053 & 0.0043 & 0.0041 & 0.0028 & 0.0032 \\
\hline \multirow[t]{8}{*}{ QLD } & 301 & 0.8138 & 0.7824 & 0.9103 & 0.8941 & 0.9208 & 0.9242 & 0.9416 & 0.9419 \\
\hline & 302 & 0.0414 & 0.0686 & 0.0245 & 0.0283 & 0.0185 & 0.0164 & 0.0145 & 0.0133 \\
\hline & 303 & 0.0368 & 0.0313 & 0.0217 & 0.0132 & 0.0276 & 0.0197 & 0.0145 & 0.0141 \\
\hline & 304 & 0.0000 & 0.0000 & 0.0000 & 0.0036 & 0.0000 & 0.0005 & 0.0000 & 0.0000 \\
\hline & 305 & 0.0000 & 0.0000 & 0.0027 & 0.0000 & 0.0000 & 0.0010 & 0.0000 & 0.0002 \\
\hline & 306 & 0.0690 & 0.0611 & 0.0154 & 0.0235 & 0.0149 & 0.0182 & 0.0131 & 0.0144 \\
\hline & 307 & 0.0391 & 0.0566 & 0.0199 & 0.0301 & 0.0164 & 0.0178 & 0.0160 & 0.0154 \\
\hline & 308 & 0.0000 & 0.0000 & 0.0054 & 0.0072 & 0.0018 & 0.0021 & 0.0003 & 0.0007 \\
\hline \multirow[t]{6}{*}{ SA } & 401 & 0.9897 & 0.9918 & 0.9857 & 0.9801 & 0.9571 & 0.9650 & 0.9821 & 0.9808 \\
\hline & 402 & 0.0000 & 0.0000 & 0.0072 & 0.0000 & 0.0000 & 0.0000 & 0.0000 & 0.0009 \\
\hline & 403 & 0.0000 & 0.0000 & 0.0000 & 0.0040 & 0.0343 & 0.0267 & 0.0143 & 0.0113 \\
\hline & 404 & 0.0000 & 0.0000 & 0.0000 & 0.0040 & 0.0070 & 0.0048 & 0.0026 & 0.0042 \\
\hline & 405 & 0.0000 & 0.0000 & 0.0000 & 0.0000 & 0.0000 & 0.0009 & 0.0005 & 0.0014 \\
\hline & 406 & 0.0103 & 0.0082 & 0.0072 & 0.0120 & 0.0017 & 0.0027 & 0.0005 & 0.0014 \\
\hline \multirow[t]{9}{*}{ WA } & 501 & 0.9022 & 0.9067 & 0.9846 & 0.9320 & 0.9447 & 0.9630 & 0.9593 & 0.9625 \\
\hline & 502 & 0.0326 & 0.0267 & 0.0000 & 0.0052 & 0.0155 & 0.0125 & 0.0256 & 0.0182 \\
\hline & 503 & 0.0109 & 0.0133 & 0.0038 & 0.0052 & 0.0205 & 0.0105 & 0.0020 & 0.0023 \\
\hline & 504 & 0.0000 & 0.0000 & 0.0000 & 0.0000 & 0.0000 & 0.0000 & 0.0000 & 0.0000 \\
\hline & 505 & 0.0109 & 0.0133 & 0.0000 & 0.0000 & 0.0000 & 0.0000 & 0.0013 & 0.0021 \\
\hline & 506 & 0.0000 & 0.0000 & 0.0077 & 0.0052 & 0.0075 & 0.0067 & 0.0053 & 0.0052 \\
\hline & 507 & 0.0217 & 0.0133 & 0.0000 & 0.0026 & 0.0044 & 0.0022 & 0.0013 & 0.0020 \\
\hline & 508 & 0.0217 & 0.0267 & 0.0038 & 0.0497 & 0.0037 & 0.0032 & 0.0038 & 0.0059 \\
\hline & 509 & 0.0000 & 0.0000 & 0.0000 & 0.0000 & 0.0037 & 0.0019 & 0.0013 & 0.0017 \\
\hline \multirow[t]{3}{*}{ TAS } & 601 & 0.7692 & 0.7273 & 0.6949 & 0.6374 & 0.8054 & 0.7728 & 0.8629 & 0.8436 \\
\hline & 602 & 0.1154 & 0.1091 & 0.2542 & 0.2967 & 0.1829 & 0.2037 & 0.1247 & 0.1254 \\
\hline & 603 & 0.1154 & 0.1636 & 0.0508 & 0.0659 & 0.0117 & 0.0235 & 0.0124 & 0.0309 \\
\hline \multirow[t]{2}{*}{ NT } & 701 & 0.9302 & 0.8605 & 0.9143 & 0.9326 & 0.9388 & 0.8605 & 0.8590 & 0.8568 \\
\hline & 702 & 0.0698 & 0.1395 & 0.0857 & 0.0674 & 0.0612 & 0.1395 & 0.1410 & 0.1432 \\
\hline $\mathrm{ACT}$ & 801 & 1.0000 & 1.0000 & 1.0000 & 1.0000 & 1.0000 & 1.0000 & 1.0000 & 1.0000 \\
\hline
\end{tabular}


